\title{
TECHNICAL, INFORMATION AND INNOVATION RISKS OF INDUSTRY 4.0 IN SMALL AND MEDIUM-SIZED ENTERPRISES - CASE OF SLOVAKIA AND POLAND
}

\author{
Vytautas SNIEŠKA (D) 1 , Valentinas NAVICKAS ${ }^{\circledR 1}{ }^{*}$, Katarína HAVIERNIKOVÁ (D)2, \\ Małgorzata OKRĘGLICKA (D) ${ }^{3}$, Waldemar GAJDA (D)4 \\ ${ }^{1}$ School of Economics and Business, Kaunas University of Technology, Kaunas, Lithuania \\ ${ }^{2}$ Department of Economy and Economics, Faculty of Social and Economic Relations, \\ Alexander Dubček University of Trenčín, Trenčín, Slovakia \\ ${ }^{3}$ Department of Economics, Investments and Real Estate, Faculty of Management, \\ Czestochowa University of Technology, Częstochowa, Poland \\ ${ }^{4}$ Warsaw Management School - Graduate and Postgraduate School, Warszaw, Poland
}

Received 20 September 2019; accepted 12 February 2020

\begin{abstract}
The implementation of Industry 4.0 concept brings many risks mainly for small and medium-sized enterprises (SMEs). The objective of the study is a diagnosis and comparison of the perception of selected risk issues connected with Industry 4.0 implementation in Slovak and Polish SMEs, which have knowledge or experience with cluster cooperation. This category of SMEs is specific due to the fact, that not all of the SMEs have experience with cluster cooperation or know this form of doing business. For this purpose, the questionnaire survey of 787 respondents was conducted, focused on the risks of Industry 4.0 that are the most important for SMEs included in three categories: technical readiness, risks of innovation and risks of information. The statistical analysis of the survey results with the application of software STATISTICA and Social Science Statistics calculator leads to the conclusion that, except for the kind of risk of "New products and services", all the observed risks are perceived as higher by Slovak SMEs than by Polish SMEs. The novelty of this research and its contribution to the body of knowledge lies in identification and evaluation of most important risks for specific group of SMEs related to Industry 4.0 implementation compared in two countries. The results of this research provide useful information for the practical fine-tuning of the policy aimed at transfer to Industry 4.0 in specific field - cluster cooperation, depending on the size of the enterprise.
\end{abstract}

Keywords: technical risk, information risk, innovation risk, risk management, Poland, Slovakia.

JEL Classification: G32, M15, O33.

*Corresponding author. E-mail: valna@ktu.lt 


\section{Introduction}

The trends of the 21st century - such as the shorter and shorter product life-cycles while consumers require more complex, unique products of ever better quality - presents numerous challenges to production (Kovács \& Kot, 2016). The Industry 4.0 concept is the answer to these challenges as the digital transformation of manufacturing fosters not only production quality and efficiency (Colledani et al., 2014) but also improves business flexibility, agility and responsiveness to internal disturbances and changes in the external environment (Babiceanu \& Seker, 2016).

The majority of the available academic and consulting studies concentrates on large companies and considers SMEs in a similar way in their evolutionary path towards Industry 4.0. However, SMEs frequently face various challenges and barriers compared to larger companies (Wadhwa, 2012). In addition, the review of the literature indicates that SMEs are often overwhelmed by both strategic and operational decisions about the implementation of different Industry 4.0 technologies into their manufacturing and/or service business and operational models (Mittal et al., 2019). SMEs often have problems with resources to develop new ventures outside their existing competencies. It is pointed that they have problems with becoming skilled in the applications and technologies of Industry 4.0 (Vrchota et al., 2019). Limited resources case that, usually, they are not early adopters, because they feel not strong enough to invest in unverified technologies or implementing inadequate practices. However, the strength of SMEs is visible in fast learning from experiences of large enterprises in the area of the emerging technologies or digital practices (Mittal et al., 2018).

SMEs are the driving force of a number of manufacturing economies. In practice, still few enterprises from the SME sector are keen on truly adopting Industry 4.0 solutions. Although they have started with the first phases of Industry 4.0 implementation, the most of the SMEs have realized optimizations but without holistic strategy. There is high level of uncertainty among SMEs about what the Industry 4.0 implementation really requires. For example, Sommer (2015) found that two-thirds of more than a thousand surveyed industries in Germany, Austria, and Switzerland are not aware of the principles of Industry 4.0 technologies and their enabling business and operating models. If SMEs cannot align to Industry 4.0 solutions, this can seriously affect the economic growth of the country. SMEs tend to overestimate the complexity of Industry 4.0 solutions and underestimate their advantages, mostly since they assume that Industry 4.0 is the concept which is not suitable to them.

Clusters can be described as useful policy tool for the Industry 4.0 implementation. It could be indicated that cluster attributes fit perfectly into Industry 4.0 challenges, and the properties of clusters can become drivers of Industry 4.0 development. Such features of Industry 4.0 as knowledge generation and dissemination seem to come to terms with the characteristics of clusters when dealing with innovative processes. The new business models characteristic for Industry 4.0 such as the connected organizations with vanishing boundaries and the emergence of digital business ecosystems can be noticed in mechanisms associated with clusters. Clusters can provide an advantageous environment for knowledge creation and dissemination, for the implementation of advanced projects, and for platforms or networks architecture (Götz, 2019). 
SMEs often belong to the largest number of clusters' stakeholders. Clusters, thanks to the advantages that provide also for SMEs, such as knowledge base and mechanisms, agglomeration economies and externalities and favourable more stable, may facilitate the digital transformation, particularly its phasing-in and testing phases. These are mainly the clusters that have knowledge base in the field of IT solutions, robotics, and automatics and so on (Götz \& Jankowska, 2017). As the backbone of the manufacturing industry, the influence of Industry 4.0 on the SMEs also in case of cluster cooperation is significant.

The primary objective of the article is a diagnosis and comparison of perception the selected risk issues connected with Industry 4.0 implementation in Polish and Slovak SMEs, which have knowledge or experience with cluster cooperation. Such an international research, even for socially and economically similar countries, is important due to the differences in approach and management methods diagnosed many times. Pointing main differences and similarities in risk perception for different business groups it allows implementing best solutions form other countries in areas, where they would be effective. Müller, Kiel, and Voigt (2018) confirmed this statement, writing that there is a lack a differentiated analysis of Industry 4.0 solutions with regard to selected variables as company sizes, nationality, industry sectors etc. This achievement become a research contribution to the body of knowledge. The conducted research confirmed significant differences in the perception of selected risks in both countries, which should be analysed both by managers and policy makers (especially in Slovakia) to prepare the necessary tools and procedures for risks reduction, and thus promoting the idea of Industry 4.0.

This article is structured as follows. Section 1 consists of the literature review that provides the brief introduction to the research area and it was useful for construction of used questionnaire survey. Section 2 introduces the methodology that was used for processing of this article. In this part we briefly described the problem statement, we derived article objectives and we provided the research procedure. In this section, we stated hypotheses for the main aim of this article achievement. Section 3 provides main results of this research. It consists of SMEs' perception of selected risk issues related to Industry 4.0 implementation and assessment of stated hypothesis by using statistical methods. Finally, the article is finished by our conclusions.

\section{Literature review}

\subsection{Industry 4.0}

Industry 4.0 combines the advantages of optimized industrial manufacturing with advanced Internet technologies to create competitive advantages for organizations, and it is characterized by smart manufacturing and smart factories (Hamada, 2019). Modularization, self-regulation, and digital integration across enterprise functions and within and beyond the organizational boundaries could be indicated as the basic principles of Industry 4.0 (Prause, 2019).

The concept of Industry 4.0 assumes blurring the differences between the work of people and the work of machines. Industry 4.0 is getting the centre of attention in relation to the future of production systems in developed countries and to its economic and social implications. It is regarded as the new fundamental paradigm shift in industrial production. In spite 
of its growing popularity and great expectations in terms of innovation impact, the concept of Industry 4.0 is still strongly linked to technologies and frameworks that have been heavily investigated and analysed in the last decades (Chiarello et al., 2018; Masarova et al., 2018). However, Industry 4.0 seems to be more than only the recombination or re-labelling of existing technologies, and create quite novel digital reality.

The term Industry 4.0 is defined as a new level of organization and control over the entire value chain of the product life cycle. The primary objective of Industry 4.0 is to satisfy the needs of individual customers, which affects numerous areas, from management, research and development, manufacturing commissioning to delivery to product utilization and recycling (Vaidya et al., 2018). Cyber-physical production systems, until now, have represented the most advanced stage of a gradual convergence between manufacturing technologies and information and communication technologies (ICTs) (Tao et al., 2017), allowing for vertical and horizontal connectedness of business functions and operations within organizations and across the global value chain. However, Industry 4.0 development could be successful if it were complemented by adequate organizational changes, changes in management techniques and an appropriate adjustment of organization strategy (Colledani et al., 2014).

Industry 4.0 is explained widely as a new industrial stage at which there is an integration between manufacturing operations systems and ICTs (Jeschke et al., 2017), which has impact on the rules of competition, the structure of industry and demands of customers. The modification of the rules of competition is due to the establishing of the reframed organizations business models with the adoption of Internet of Things concepts and digitization of factories (Dalenogare et al., 2018). In the market terms, digital technologies allow enterprises to offer new digital solutions for customers, such as internet-based services embedded in products (Coreynen et al., 2017).

\subsection{Technical, information and innovation risks within Industry 4.0 solutions}

Effective risk management is the key component of any successful management strategy. Risk management is a systematic process that helps organizations to grasp the essence of risk and the adequate ways of its assessment and control. Risk management should be analyzed in an organization holistically and not in an ad-hoc manner by business operation or by risk type. Risk management must be conducted in a structured way, integrated within the enterprise; this is why the ERM approach is increasingly popular in enterprise risk management in organizations (Ching \& Colombo, 2014; Kordos, 2018).

The concept of Industry 4.0 reacts to the new threats in the environment by creation of new types of risks. The combination of cyber-space, more and more complex technologies and manufacturing of elements, and using outsourcing for many business activities is the key factor increasing hazards in business operation (Tupa et al., 2017). Moreover, the empirical results indicate that risks in terms of Industry 4.0 are perceived differently by SMEs, particularly since they do not fully grasp the opportunities of new business models as opposed to larger enterprises (Yan, 2017).

The potential risks of Industry 4.0 are one of the main reasons pointed out as those hampering or questioning the Industry 4.0 implementation. From the economic point of view, the loss of competitive advantage through diminishing business models, resulting in shrinking 
profits or even the relocation of manufacturing is mentioned among the results of the Industry 4.0 implementation (Ghanbari et al., 2017). Besides, social risks are indicated, including required training and the requalification of the workforce or potential job losses, particularly for routine or simple occupations replaced by machines (Kazancoglu \& Ozkan-Ozen, 2018). New reality causes that it is essential to completely identify emerging risks in Industry 4.0 and approach them with suitable measures. Only then will companies be successful in the long-term perspective (Schröder et al., 2014).

The implementation of Industry 4.0 solutions faces a variety of technological risks. A modern organization faces many challenges resulting from growing technical complexity connected with the strengthening of the linkages between the mechanical and IT systems in a supply chain. The whole process is more effective when elements in mechanical system are adapted to digitalization. However, SMEs often try to convert purely mechanical machines into element of fully automatic system because of avoiding costs of new assets' purchase. Such a solution can reduce the costs of the Industry 4.0 implementation but the technical complexity (and risk) arises significantly. The other problem for SMEs adopting Industry 4.0 solutions is a great dependency on technology and software, which are vulnerable to a system failure or errors disrupting the proper functioning of the entire supply chain. No less significant problem is generated by the need for unification or compatibility of standards in all organizational units and systems operations when SMEs attempt to the technical integration of Industry 4.0 (Birkel et al., 2019; Grenčíková et al., 2019). When previously SME success could be based on production assets characterised by low level of digitalization and effective organization of the production process, nowadays it seems to be not enough to achieve competitive advantage. In the age of Industry 4.0, the relevant data transparency is required across the supply chain, whereas existing systems might not be easily compatible, and adjustment to technological advancement is risky and absorbs a lot of financial resources. However, the need of increased data volumes and availability in real time causes that modern infrastructures and proper adaptations are required to information processing. All the processes of the organization are determined by new technological solutions as well as risk-bearing. Humans, objects and systems merging into a coherent whole is necessary to form dynamic, real-time optimized and self-organizing, cross-company value creation networks (Tupa et al., 2017).

One of those risks is virtual attack. The application of information and communication technology in the creation of industrial value opens the gates to attacks from the virtual world. Therefore, preparations must be made in order to reduce these risks on a technical and organizational level. Other risks arise by data protection. Since it is necessary to protect intellectual property, competitive advantages can be lost if information is taken over by competitors (Birkel et al., 2019).

In the environment characterized by high competition, survival is guaranteed only to those companies, which realize the importance of constant innovation (Pavlović et al., 2018). The innovation activities of the enterprise were determined by the knowledge and technology at their disposal. However, enterprises were not extremely interested in changing their successful business model and the established relations with their customers by innovation implementation (Jovović, 2017). The Industry 4.0 idea is strictly connected with innovations, especially in the technology area, but also in the business organization area. Innovative ac- 
tiveness needs to be included and connected in the Industry 4.0 solutions. In addition, the systemic understanding of innovation policy is required, which should include strategy and coordinated implementation. In addition, when launching Industry 4.0, one should not ignore the rights of employees to participate. This could be treated as the basis for acceptance of innovations among employees (Schröder et al., 2014). However, innovations are always connected with increased risk. In particular, technological innovation activity contains uncertain factors at each stage and components, giving it high-risk. The probability of a successful technological innovation is often less than the probability of failure. Technological innovation risks is mostly due to uncertainties of technology, market, innovation benefits and institutional environment. Technological innovation projects comprise decision uncertainty, complexity, multiple objectives, and dynamic interactions (Wu et al., 2010).

As Industry 4.0 brought a new kind of risks or new risk distribution, a systematic consideration of risks and effective risk management are particularly essential.

\section{Methodology}

\subsection{Problem statement and article objective}

The concept of Industry 4.0 has begun to be enforced also in Poland and Slovakia. SMEs that carry out their activities in these countries have possibilities to fit this new industrial trend. SMEs play an indispensable role in development of many economic branches and contribute to overall potential of a competitive environment (Korcsmáros et al., 2017). Although the SMEs are flexible, they have not enough experience, they lack of knowledge and shortage of resources for implementation of the Industry 4.0 solution. Many activities in this process are risky for SMEs. Nowadays important role also in case of Industry 4.0 implementation plays the connection of SMEs into clusters. There are the new knowledge and innovation related to information and communication technologies in clusters' environment, which contribute to the transformation of SMEs into smart entities.

This article captured the opinions of Polish and Slovak SMEs on the selected risks related to the implementation of the Industry 4.0 concept. It is a part of the VEGA research project No 1/0918/16 "Risk management of SMEs in the context of clusters' involvement activities in the Slovak Republic". Within its framework, the questionnaire survey oriented on SMEs that have knowledge or experience with cluster cooperation was conducted. In order to achieve the main objective of the article, this research is focused on the risks that are related to the concept of Industry 4.0 and their implementation in SMEs. Following Birkel et al. (2019), Müller and Däschle (2018), Mura and Mazák (2018), and Tupa et al. (2017) three categories of risks were observed: technical readiness, risks of innovation process and risks of IT.

\subsection{Research sample and procedure}

The structure of the Polish and Slovak SMEs that were involved in the survey is listed in Table 1. The questionnaires were distributed among 487 Slovak and 300 Polish SMEs representing by their owner or manager. We focused on SMEs that belonged to the manufacturing industry. The sampling selection was realized following Borrego, Douglas, and Amelink 
(2009), Heckathorn (2011), Haseeb et al. (2019) and Pejić Bach et al. (2019). The estimation of range selection was calculated according formula (1) from Cochran (1977):

$$
n=\frac{t_{\alpha}^{2} \times p \times(1-p)}{d^{2}},
$$

where: $n$ - the requested sample size, $t_{\alpha}$ - the coefficient of reliability for the chosen reliability a (while $\alpha=1.96$ ), $d$ - desired level of precision, $p$ - the estimated proportion of an attribute that is present in the population.

Within the results of realized project VEGA No 1/0918/16, we found out that in 2018, there were 119 SMEs in clusters in the Slovak republic and 854 in Polish clusters.

The research sample for both countries were calculated according formula (1), while $p=4 \%$. The research sample for Slovakia should be 47 SMEs in Slovakia and 114 SMEs in Poland if we take into consideration only SMEs that have experience with cluster cooperation. Due to the objectives of project VEGA No 1/0918/16, this research has limitation in research sampling; because we take into account also SMEs, which have knowledge about cluster cooperation. The selection of respondents due to their specificity was realized on the principle of snow ball method, This method is used also by authors as Heckathorn (2011), Haseeb et al. (2019), Pejić Bach et al. (2019). The sample error was calculated from total population of SMEs at $95 \%$ confidence level and 50\% of sample proportion. For Slovakia it was calculated at level $4.4 \%$ and for Poland at level 5.7\%.

The surveys were collected in years 2017-2018.

Table 1. Structure of Polish and Slovak respondents

\begin{tabular}{|l|c|c|c|c|c|c|c|c|}
\hline \multirow{2}{*}{ Country } & \multicolumn{2}{|c|}{ Micro enterprises } & \multicolumn{2}{|c|}{ Small enterprises } & \multicolumn{2}{|c|}{ Medium enterprises } & \multicolumn{2}{|c|}{ Total } \\
\cline { 2 - 9 } & $\%$ & $\begin{array}{c}\text { Number of } \\
\text { respondents }\end{array}$ & $\%$ & $\begin{array}{c}\text { Number of } \\
\text { respondents }\end{array}$ & $\%$ & $\begin{array}{c}\text { Number of } \\
\text { respondents }\end{array}$ & $\%$ & $\begin{array}{c}\text { Number of } \\
\text { respondents }\end{array}$ \\
\hline Poland & 18.8 & 148 & 14.7 & 116 & 4.6 & 36 & 38.1 & 300 \\
\hline Slovakia & 22.1 & 174 & 20.7 & 163 & 19.1 & 150 & 61.9 & 487 \\
\hline Total & 40.9 & 322 & 35.5 & 279 & 23.6 & 186 & 100 & 787 \\
\hline
\end{tabular}

Within the project, the questionnaire was designed and distributed and it also included the questions related to the awareness of Industry 4.0 and covered the questions including the level of risks related to the implementation of the Industry 4.0 concept in SMEs. Due to the fact, that Industry 4.0 is not the core of the project, we focused on selected issues of this topic.

The success of the Industry 4.0 implementation depends on a high level of knowledge regarding its concept (main functions, core technologies). Within the "Question 1: Do you know the concept of Industry 4.0?" SMEs provided information about their awareness regarding the concept of Industry 4.0 in line with their activities. SMEs expressed their perception by using a three-point scale: 1 - I aware, 2 - I aware of it partially, 3 - I don't aware.

The launch of the Industry 4.0 concept into activities of SMEs is affected by various risks. The most important are three risk categories: technical readiness for the Industry 4.0 implementation, innovation capabilities and readiness for digitalization. Each category consists of 
several specific risks. Corresponding with it, the following questions were evaluated: "Question 2: How do you perceive risks related to technical readiness for Industry 4.0 implementation." The respondents evaluated risks: technical complexity, retrofitting and system failure. "Question 3: How do you perceive IT risks related to the implementation of the Industry 4.0 concept?" Evaluated risks: technical solutions and data handling. "Question 4: How do you perceive risks influenced by innovation activities?" Evaluated risks: service orientation - new products and services, using new technologies and the capital requirement.

Respondents expressed their attitudes towards the questions by using the six-point Likert scale from 0 - risk doesn't apply to an enterprise, 1 - the lowest level of risk to 5 - the highest level of risk.

The outcome of the single questionnaire results was treated through descriptive statistics (mean, standard deviation and mode). To explore the differences between Slovak and Polish SMEs the Mann-Whitney U test (in the tables MWU) was calculated. This test was used due to the fact that the data were not normally distributed (this was confirmed by using Shapiro Wilk test $\mathrm{p}$ value - in the tables SWT). We set null hypothesis about the non-existence of statistical significant differences in the perception of Slovak and Polish SMEs' and the alternative hypothesis that means opposite statement. If the calculated value was lower than confidence level 5\%, we rejected the null hypothesis and accepted the alternative hypothesis. Following research work of Civelek, Ključnikov, Krištofík, and Rozsa (2019), the significance of differences between Slovak and Polish respondents' answers were evaluated by using Z score test for 2 population proportions. The calculations were carried out using statistical software STATISTICA and free calculator of Social Science Statistics.

Following hypotheses were tested to explore the differences in Polish and Slovak SMEs' perceptions:

H1: There is no statistically significant difference between the Slovak and Polish SMEs' awareness regarding the implementation of Industry 4.0.

$\mathrm{H} 2$ : There is no statistical significant difference between respondents' answers in relation with perception of selected risk kinds.

\section{Results}

The discussion and initiatives that promote the phenomenon of Industry 4.0 are increasing among researchers, professionals, entrepreneurs and policy makers around the world. Its successful embracing requires high level of information. Table 2 shows how Polish and Slovak SMEs are aware of the main features and solutions of this concept (the evaluation of Question 1). More than $60 \%$ of the respondents have necessary knowledge and information. Due to the results of MW $\mathrm{U}$ test we accepted the alternative hypotheses. There is the existence of differences between Polish and Slovak SMEs' awareness regarding the implementation of Industry 4.0. The $\mathrm{Z}$ score confirmed that differences between their perceptions are statistically significant.

The technological adoption of the Industry 4.0 concept is linked to many requirements that are necessary to fulfil transformation of enterprise through digitalization and exploitation of the potential of new technologies. The risks, connected with this issue, we evaluated in Question 2. 
Table 2. The level of awareness regarding Industry 4.0

\begin{tabular}{|l|c|c|c|}
\hline \multirow{2}{*}{ Scale } & \multicolumn{2}{|c|}{ Frequency (\%) } & \multirow{2}{*}{ Z score } \\
\cline { 2 - 3 } & PL & SK & 0.000 \\
\hline I aware & 60.67 & 74.33 & 0.001 \\
\hline I aware it partially & 34.00 & 23.20 & 0.035 \\
\hline I don't aware & 5.33 & 2.46 & \\
\hline$\mu$ & 1.45 & 1.28 & \multirow{2}{*}{-} \\
\hline SD & 0.60 & 1 & \\
\hline mode & 1 & 0.50 & \\
\hline SWT & 0.000 & 0.000 & \\
\hline MWU & \multicolumn{2}{|c|}{} \\
\hline
\end{tabular}

The implementation of Industry 4.0 in SMEs is related to high level of their technical complexity. This kind of risks was perceived as a very high risk only by $11.33 \%$ of Polish and $14.58 \%$ of Slovak respondents. The results of MW U test confirmed the differences in Polish and Slovak respondents' perception. The statistical significance of these differences was not confirmed for the highest and low level of this kind of risks.

Table 3. The technical complexity, the retrofitting and the system failure of SMEs

\begin{tabular}{|c|c|c|c|c|c|c|c|c|c|}
\hline \multirow{3}{*}{ Scale } & \multicolumn{3}{|c|}{ The technical complexity } & \multicolumn{3}{|c|}{ The retrofitting } & \multicolumn{3}{|c|}{ The system failure } \\
\hline & \multicolumn{2}{|c|}{ Frequency (\%) } & \multirow{2}{*}{$\mathrm{Z}$ score } & \multicolumn{2}{|c|}{ Frequency (\%) } & \multirow{2}{*}{ Z score } & \multicolumn{2}{|c|}{ Frequency (\%) } & \multirow{2}{*}{ Z score } \\
\hline & PL & SK & & PL & SK & & PL & SK & \\
\hline 0 & 18.67 & 10.88 & 0.002 & 20.67 & 12.53 & 0.002 & 16.00 & 9.03 & 0.003 \\
\hline 1 & 22.67 & 12.32 & 0.000 & 17.33 & 7.80 & 0.000 & 20.67 & 10.68 & 0.000 \\
\hline 2 & 20.67 & 16.02 & 0.097 & 18.67 & 12.94 & 0.029 & 18.67 & 12.94 & 0.030 \\
\hline 3 & 15.33 & 24.02 & 0.004 & 15.33 & 21.36 & 0.037 & 16.67 & 20.53 & 0.180 \\
\hline 4 & 11.33 & 22.18 & 0.000 & 17.33 & 26.08 & 0.005 & 14.67 & 21.97 & 0.011 \\
\hline 5 & 11.33 & 14.58 & 0.194 & 10.67 & 19.10 & 0.002 & 13.33 & 24.85 & 0.000 \\
\hline$\mu$ & 2.12 & 2.78 & \multirow{5}{*}{-} & 2.23 & 2.98 & \multirow{5}{*}{$\begin{array}{l}- \\
-\end{array}$} & 2.33 & 3.10 & \multirow{5}{*}{ - } \\
\hline SD & 1.61 & 1.55 & & 1.66 & 1.61 & & 1.64 & 1.61 & \\
\hline mode & 1 & 3 & & 0 & 4 & & 1 & 5 & \\
\hline SWT & 0.000 & 0.000 & & 0.000 & 0.000 & & 0.000 & 0.000 & \\
\hline MWU & \multicolumn{2}{|c|}{0.000} & & \multicolumn{2}{|c|}{0.000} & & \multicolumn{2}{|c|}{0.000} & \\
\hline
\end{tabular}

From the technical point of view the retrofitting of existing machinery presents large technical challenges. For example, purely mechanical machines need to be converted so that they could be operated automatically. Table 3 presents the SMEs' perception of this kind of risks. $19.10 \%$ of Slovak respondents perceived these risks as the most important and $20.67 \%$ of Polish respondents they did not apply in their business. The p-value of MW U test confirmed the differences in the respondents' answers and $\mathrm{Z}$ score confirmed that the differences between their perceptions are statistically significant. 
The risks related to system failure reflects the situation, what if the system, which is prerequisite for many part, fails. How these risks were perceived in the research is presented in Table 3. The p-value of MW $U$ test confirmed the differences in the respondents' answers and $\mathrm{Z}$ score confirmed that the differences between their perceptions are not statistically significant in case of middle level of the risk.

In Question 3 we focused on two risks: technical solutions and data handling (Table 4). Technical solutions represent bare infrastructure and smart solutions for the interaction between physical systems and humans, reflection of physical objects in the information world. Transaction in terms of software services, interoperation that is enabled by interacting, cloud-based platforms, prescription to handle big data with the goal of retrieving new and unexpected information and communication using the concepts and solutions coming from the network architecture (Neugebauer et al., 2016). The perception of this kind of risks among respondents is at low level. $32.00 \%$ of Polish respondents do not observe it in their activities and $27.52 \%$ of Slovak respondents perceived these risks at middle level of rating scale. The differences between Polish and Slovak SMEs' perception were also confirmed by MW U test and $\mathrm{Z}$ score confirmed the significant differences except for the perception at low level.

The concept of Industry 4.0 includes big data that need to be collected, processed, transported, integrated, transformed, stored, computed and enhanced. This process is connected with various levels of risk. The results of data handling risk perception by SMEs are showed in Table $4.32 .00 \%$ of Polish respondents perceived this kind of risks as risk with very low impact on their activities and $26.49 \%$ of Slovak respondents perceived it as a risk with middle impact. The results MW U Test showed the differences between Polish and Slovak SMEs' answers. There is no statistical significance of risk perception at low and the highest level.

Table 4. Technical solutions and data handling of SMEs

\begin{tabular}{|c|c|c|c|c|c|c|}
\hline \multirow{3}{*}{ Scale } & \multicolumn{3}{|c|}{ Technical solutions } & \multicolumn{3}{|c|}{ Data handling } \\
\hline & \multicolumn{2}{|c|}{ Frequency (\%) } & \multirow{2}{*}{ Z score } & \multicolumn{2}{|c|}{ Frequency (\%) } & \multirow{2}{*}{ Z score } \\
\hline & PL & SK & & PL & SK & \\
\hline 0 & 32.00 & 11.09 & 0.000 & 16.67 & 10.27 & 0.009 \\
\hline 1 & 29.33 & 16.43 & 0.000 & 32.00 & 16.63 & 0.000 \\
\hline 2 & 19.33 & 22.38 & 0.308 & 24.67 & 26.28 & 0.617 \\
\hline 3 & 7.33 & 27.52 & 0.000 & 14.67 & 26.49 & 0.000 \\
\hline 4 & 10.67 & 14.37 & 0.134 & 7.33 & 13.55 & 0.007 \\
\hline 5 & 1.33 & 8.21 & 0.000 & 4.67 & 6.78 & 0.418 \\
\hline$\mu$ & 1.39 & 2.42 & \multirow{5}{*}{-} & 1.78 & 2.37 & \multirow{5}{*}{-} \\
\hline SD & 1.35 & 1.42 & & 1.34 & 1.36 & \\
\hline mode & 0 & 3 & & 1 & 3 & \\
\hline SWT & 0.000 & 0.000 & & 0.000 & 0.000 & \\
\hline MWU & \multicolumn{2}{|c|}{0.000} & & \multicolumn{2}{|c|}{0.000} & \\
\hline
\end{tabular}


The competitiveness of each business entity depends on ability to innovate. Within the Question 4, the respondents evaluated three risks related to their innovation activities in connection with Industry 4.0 (see Table 5). The concept of Industry 4.0 is also focused on the new production processes consisting in providing new products and services. The risks linked with these issues in case of Polish SMEs are mostly perceived as risks with middle level $(28.00 \%)$. The most of Slovak respondents perceive these risks without importance for their business (28.54\%). The results of MW U test showed that the differences exist between Polish and Slovak respondents' answers. The statistical significance of these differences was confirmed at assessment level of 0 and 3.

Table 5. New products and services, usage of new technologies and the capital requirement of SMEs

\begin{tabular}{|c|c|c|c|c|c|c|c|c|c|}
\hline \multirow{3}{*}{ Scale } & \multicolumn{3}{|c|}{ New products and services } & \multicolumn{3}{|c|}{ Usage of new technologies } & \multicolumn{3}{|c|}{ The capital requirement } \\
\hline & \multicolumn{2}{|c|}{ Frequency (\%) } & \multirow{2}{*}{ Z score } & \multicolumn{2}{|c|}{ Frequency (\%) } & \multirow{2}{*}{ Z score } & \multicolumn{2}{|c|}{ Frequency (\%) } & \multirow{2}{*}{ Z score } \\
\hline & PL & SK & & PL & SK & & $\mathrm{PL}$ & SK & \\
\hline 0 & 14.67 & 28.54 & 0.000 & 16.67 & 4.52 & 0.000 & 12.67 & 3.90 & 0.000 \\
\hline 1 & 20.00 & 15.61 & 0.114 & 20.67 & 11.29 & 0.000 & 14.00 & 5.54 & 0.000 \\
\hline 2 & 22.00 & 23.82 & 0.555 & 20.00 & 17.45 & 0.373 & 21.33 & 15.61 & 0.041 \\
\hline 3 & 28.00 & 16.43 & 0.000 & 24.67 & 31.62 & 0.000 & 29.33 & 28.54 & 0.810 \\
\hline 4 & 8.00 & 8.21 & 0.912 & 13.33 & 21.97 & 0.003 & 16.00 & 22.18 & 0.035 \\
\hline 5 & 7.33 & 7.39 & 0.976 & 4.67 & 12.94 & 0.000 & 6.67 & 24.23 & 0.000 \\
\hline$\mu$ & 2.17 & 1.82 & \multirow{5}{*}{-} & 2.11 & 3.13 & \multirow{5}{*}{-} & 2.42 & 3.32 & \multirow{5}{*}{ - } \\
\hline SD & 1.42 & 1.56 & & 1.44 & 2.29 & & 1.42 & 1.35 & \\
\hline mode & 3 & 0 & & 3 & 3 & & 3 & 3 & \\
\hline SWT & 0.000 & 0.000 & & 0.000 & 0.000 & & 0.000 & 0.0000 & \\
\hline MWU & \multicolumn{2}{|c|}{0.001} & & \multicolumn{2}{|c|}{0.000} & & \multicolumn{2}{|c|}{0.000} & \\
\hline
\end{tabular}

The consequences of new technologies for industrial production systems allow flexible mass custom production and flexibility in production quantity. As we can see in Table 5, in both countries, the respondents perceived this risk as risk, which affect in case of link to Industry 4.0, have moderate level. The results of MW U test showed the differences between Polish and Slovak SMEs' perception. Z score confirmed the statistical significance of the differences for all levels of risk perception except for low-level perception.

The implementation of the solutions of Industry 4.0 requires capital expenditure on new technologies. The risks of capital requirement (Table 5) belong to risks that are perceived with higher impact. Only $6.67 \%$ of Polish SMEs and $24.23 \%$ of Slovak respondents perceived these risks with very high value. The results of MW U test showed statistical differences between the respondents' answers. Z score confirmed statistical significance of differences except for the perception at middle level.

Figure 1 presents the overall evaluation of the selected risks perception by Polish and Slovak SMEs. As we can see, SMEs generally perceived the risks at low (Polish SMEs) and middle values (Slovak SMEs). The research showed that Slovak SMEs perceive observed 
risks as more risky. Except for the risks of new products and services, that was more risky for Polish SMEs.

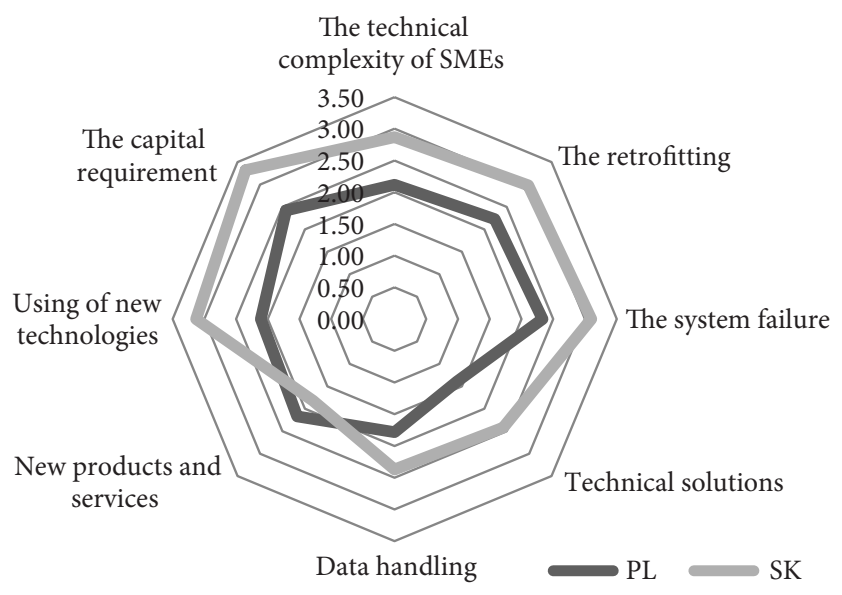

Figure 1. The overall perception of risks - average value of SMEs' answers

For the accomplishment of the main aim, two main statistical hypotheses were tested at significance p-value (0.05). From the results of tested statistics Mann Whitney $U$ test followed, that the stated hypothesis about no differences between Polish and Slovak SMEs' perception were not confirmed. The p-value of $\mathrm{Z}$ score showed in which cases the statistical significance of differences was present. As the most important risks in the context of Industry 4.0 respondents perceived the capital requirement (PL: $2.42 \pm 1.42$; SK: $3.32 \pm 1.35$ ). The less important risks is the Technical solution for Polish SMEs $(1.39 \pm 1.35)$ and the new products and services for Slovak SMEs (1.82 \pm 1.56$)$.

\section{Conclusions}

Recently, the Industry 4.0 concept has become an increasingly important issue, being discussed by academics, researchers, firms, and politicians. The introduction of this concept in enterprises should bring new technologies to improve quality, efficiency, and effectiveness of resources, reduce risks, and to remain competitive in the market.

Features of Industry 4.0 and characteristics of clusters seem to be similar or compatible in many areas. New business models developed based on Industry 4.0 concept fit perfectly to the idea of cluster cooperation and expected advantageous of it. However, studies on the subject - activity of cluster members within Industry 4.0 environment are still limited.

With the inevitable changes, which Industry 4.0 implementation will bring, there is a very high probability of new risks occurring and having negative impact on many aspects across organizations. Industry 4.0 will not take advantage of its entire potential until all its risks are well understood and clearly assessed. Moreover, businesses in some Central European countries as e.g. in Slovakia have not taken Industry 4.0's challenges into account for a long time, and from this reason, they are lagging behind West European countries. This situation requires intensified research efforts and practical action in the area to reduce the existing gap. 
Therefore, despite many advantages of Industry 4.0, in order to be able to implement it holistically, a systematic consideration of the risks is also essential. The types of risks highly visible by the Industry 4.0 implementation seem to be technical readiness, risks of innovation process and IT risks. In many aspects, the level of those kinds of risks is significantly increased because of new technological and IT solutions, and their advancement.

The results of our research showed the differences in the level of awareness regarding Industry 4.0 between Polish and Slovak SMEs. The Slovak SMEs in this research had higher level of awareness related to the Industry 4.0 implementation than Polish SMEs. In addition, the perception of risks linked with the Industry 4.0 implementation showed differences. Therefore, both Slovakia and Poland have their own specifics according to risk perception, which confirms the validity of the conducted research.

A risk diagnosis and an attempt of its reduction are not enough. It is necessary to follow the analogical problems in other sectors, type of organizations or even countries to find the existing trends and use to best practices in risk reduction. There is no doubt that the failure of a firm in risk identifying and managing will bring up a significant negative effect on business performance.

There may be some limitations in this article. From the point of view of methodology, there were mainly the limitations in research sample and prior research studies that are relevant to the focus of the project. SMEs are not a homogenous group, we focused on manufacturing SMEs and from this point of view it could be useful to analyse SMEs e.g. from the same industry. Although the SMEs create the largest part of clusters' stakeholders, not all of SMEs know this cooperation and want to join this form of doing business. From this reason and focusing of research project in which frame this research was realised, we focused only on SMEs that have knowledge or experience with cluster cooperation. The next limitation concerns the literature review. Prior studies are focused mainly of risk issues of Industry 4.0 implementation in SMEs in general, but only few studies solved this topic in case of cluster cooperation. From this reason, we focused on selected risk issues of Industry 4.0 implementation in accordance with cited studies. From this point of view, the results of this research provide useful bases for future research, which may become more focused on observed risk issues in case of SMEs, which carry out their activities in clusters. The broad implication of this article is that point on the most important risks related to Industry 4.0 implementation in SMEs.

\section{References}

Babiceanu, R. F., \& Seker, R. (2016). Big Data and virtualization for manufacturing cyberphysical systems: A survey of the current status and future outlook. Computers in Industry, 8, 128-137. https://doi.org/10.1016/j.compind.2016.02.004

Birkel, H. S., Veile, J. W., Müller, J. M., Hartmann, E., \& Voigt, K.-I. (2019). Development of a risk framework for Industry 4.0 in the context of sustainability for established manufacturers. Sustainability, 11(384), 27. https://doi.org/10.3390/su11020384

Borrego, M., Douglas, E. P., \& Amelink, C. T. (2009). Quantitative, qualitative, and mixed research methods in engineering education. Journal of Engineering Education, 98(1), 53-66.

https://doi.org/10.1002/j.2168-9830.2009.tb01005.x 
Chiarello, F., Trivelli, L., Bonaccorsi, A., \& Fantoni, G. (2018). Extracting and mapping industry 4.0 technologies using Wikipedia. Computers in Industry, 100, 244-257. https://doi.org/10.1016/j.compind.2018.04.006

Ching, H. Y., \& Colombo, T. M. (2014). Enterprise risk management good practices and proposal of conceptual framework. Journal of Management Research, 6(3), 69-85. https://doi.org/10.5296/jmr.v6i3.5404

Civelek, M., Ključnikov, A., Krištofík, P., \& Rozsa, Z. (2019). Barriers in financing microenterprises from the perspective of Czech and Slovak microentrepreneurs. Journal of Business Economics and Management, 20(2), 244-267. https://doi.org/10.3846/jbem.2019.8114

Cochran, W. G. (1977). Sampling techniques. Wiley and Sons.

Colledani, M., Tolio, T., Fischer, A., Iung, B., Lanza, G., Schmitt, R., \& Váncza, J. (2014). Design and management of manufacturing systems for production quality. CIRP Annals, 63(2), 773-796. https://doi.org/10.1016/j.cirp.2014.05.002

Coreynen, W., Matthyssens, P., \& Van Bockhaven, W. (2017). Boosting servitization through digitization: Pathways and dynamic resource configurations for manufacturers. Industrial Marketing Management, 60, 42-53. https://doi.org/10.1016/j.indmarman.2016.04.012

Dalenogare, L. S., Benitez, G. B., Ayala, N. F., \& Frank, A. G. (2018). The expected contribution of Industry 4.0 technologies for industrial performance. International Journal of Production Economics, 204, 383-394. https://doi.org/10.1016/j.ijpe.2018.08.019

Ghanbari, A., Laya, A., Alonso-Zarate, J., \& Markendahl, J. (2017). Business development in the Internet of Things: A matter of vertical cooperation. IEEE Communications Magazine, 55(2), 135-141. https://doi.org/10.1109/MCOM.2017.1600596CM

Götz, M. (2019). The Industry 4.0 induced agility and new skills in clusters. Foresight and STI Governance, 13(2), 72-83. https://doi.org/10.17323/2500-2597.2019.2.72.83

Götz, M., \& Jankowska, B. (2017). Clusters and Industry 4.0 - do they fit together? European Planning Studies, 25(9), 1633-1653. https://doi.org/10.1080/09654313.2017.1327037

Grenčíková, A., Kordoš, M., \& Sokol, J. (2019). The approach to Industry 4.0 within the Slovak business environment. Social Sciences, 8(4), 104. https://doi.org/10.3390/socsci8040104

Hamada, T. (2019). Determinants of decision-makers' attitudes toward Industry 4.0 adaptation. Social Sciences, 8(5), 140. https://doi.org/10.3390/socsci8050140

Haseeb, M., Hussain, H. I., Kot, S., Androniceanu, A., \& Jermsittiparsert, K. (2019). Role of social and technological challenges in achieving a sustainable competitive advantage and sustainable business performance. Sustainability, 11(14), 3811. https://doi.org/10.3390/su11143811

Heckathorn, D. D. (2011). Comment: Snowball versus respondent-driven sampling. Sociological Methodology, 41(1), 355-366. https://doi.org/10.1111/j.1467-9531.2011.01244.x

Jeschke, S., Brecher, C., Meisen, T., Özdemir, D., \& Eschert, T. (2017). Industrial Internet of Things and cyber manufacturing systems. In S. Jeschke, C. Brecher, H. Song, \& D. B. Rawat (Eds.), Industrial internet of things (pp. 3-19). Springer Series in Wireless Technology. Springer. https://doi.org/10.1007/978-3-319-42559-7_1

Jovović, D. (2017). Model of open innovations and small and medium-sized enterprises development. Facta Universitatis, Series: Economics and Organization, 14(4), 345-357. https://doi.org/10.22190/FUEO1704345J

Kazancoglu, Y., \& Ozkan-Ozen, Y. D. (2018). Analyzing Workforce 4.0 in the Fourth Industrial Revolution and proposing a road map from operations management perspective with fuzzy DEMATEL. Journal of Enterprise Information Management, 31(6), 891-907.

https://doi.org/10.1108/JEIM-01-2017-0015 
Korcsmáros, E., Mura, L., \& Šimonová, M. (2017). Identification of small and medium-sized enterprises development in Slovakia. Journal of Applied Economic Sciences, 12(6), 1702-1712. https://doi.org/10.24136/oc.v8i2.16

Kordos, M. (2018, May 17-18). Risk assessment of SMEs under engaging in cluster cooperation in terms of their territorial impact in Slovakia within the EU context. In Proceedings of the $4^{\text {th }}$ International Conference on European Integration 2018 (ICEI 2018) (pp. 773-780). Ostrava, Czech Republic.

Kovács, G. Y., \& Kot, S. (2016). New logistics and production trends as the effect of global economy changes. Polish Journal of Management Studies, 14(2), 115-126. https://doi.org/10.17512/pjms.2016.14.2.11

Masarova, T., Kordos, M., \& Sokol, J. (2018, November 22). The impact of Industry 4.0 initiative on society. In Proceedings of International Scientific Conference on the Impact of Industry 4.0 on Job Creation (pp. 155-161). Trencianske Teplice, Slovakia.

Mittal, S., Khan, M. A., Romero, D., \& Wuest, T. (2018). A critical review of smart manufacturing \& Industry 4.0 maturity models: Implications for small and medium-sized enterprises (SMEs). Journal of Manufacturing Systems, 49, 194-214. https://doi.org/10.1016/j.jmsy.2018.10.005

Mittal, S., Khan, M. A., Romero, D., \& Wuest, T. (2019). Smart manufacturing: Characteristics, technologies and enabling factors. Journal of Engineering Manufacture, 233(5), 1342-1361. https://doi.org/10.1177/0954405417736547

Müller, J. M., \& Däschle S. (2018). Business model innovation of Industry 4.0 solution providers towards customer process innovation. Processes, 6(12), 260. https://doi.org/10.3390/pr6120260

Müller, J. M., Kiel, D., \& Voigt, K.-I. (2018). What drives the implementation of Industry 4.0? The role of opportunities and challenges in the context of sustainability. Sustainability, 10(1), 247. https://doi.org/10.3390/su10010247

Mura, L., \& Mazák, M. (2018). Innovative activities of family SMEs: Case study of the Slovak regions. Online Journal Modelling the New Europe, 27, 132-147. https://doi.org/10.24193/OJMNE.2018.27.06

Neugebauer, R., Hippmann, S., Leis, M., \& Landherr, M. (2016). Industrie 4.0 - From the perspective of applied research. Procedia CIRP, 57(1), 2-7. https://doi.org/10.1016/j.procir.2016.11.002

Pavlović, M., Radosavljević, M., \& Milojević, R. (2018). The role of information technology in the implementation of lean concept. Facta Universitatis. Series: Economics and Organization, 15(4), 349-362. https://doi.org/10.22190/FUEO1804349P

Pejić Bach, M., Bosilj Vukšić, V., Suša Vugec, D., \& Stjepić, A. M. (2019). BPM and BI in SMEs: The role of BPM/BI alignment in organizational performance. International Journal of Engineering Business Management, 11, 1847979019874182. https://doi.org/10.1177/1847979019874182

Prause, M. (2019). Challenges of Industry 4.0 technology adoption for SMEs: The case of Japan. Sustainability, 11(20), 5807. https://doi.org/10.3390/su11205807

Schröder, M., Indorf, M., \& Kersten, W. (2014, November 15-18). Industry 4.0 and its impact on supply chain risk management. In Proceedings of the $14^{\text {th }}$ International Conference Reliability and Statistics in Transportation and Communication (RelStat'14) (pp. 35-36). Riga, Latvia.

Sommer, L. (2015). Industrial revolution - Industry 4.0: Are German manufacturing SMEs the first victims of this revolution? Journal Industrial Engineering Management, 8(5), 1512-1532. https://doi.org/10.3926/jiem.1470

Tao, F., Cheng, Y., Zhang, L., \& Nee, A. Y. (2017). Advanced manufacturing systems: Socialization characteristics and trends. Journal of Intelligent Manufacturing, 28(5), 1079-1094. https://doi.org/10.1007/s10845-015-1042-8

Tupa, J., Simota, J., \& Steiner, F. (2017). Aspects of risk management implementation for Industry 4.0. Procedia Manufacturing, 11, 1223-1230. https://doi.org/10.1016/j.promfg.2017.07.248 
Vaidya, S., Ambad, P., \& Bhosle, S. (2018). Industry 4.0 - a glimpse. Procedia Manufacturing, 20, 233238. https://doi.org/10.1016/j.promfg.2018.02.034

Vrchota, J., Volek, T., \& Novotná, M. (2019). Factors introducing industry 4.0 to SMES. Social Sciences, 8(5), 10. https://doi.org/10.3390/socsci8050130

Wadhwa, R. (2012). Flexibility in manufacturing automation: A living lab case study of Norwegian metal casting SMEs. Journal of Manufacturing Systems, 31(4), 444-454. https://doi.org/10.1016/j.jmsy.2012.07.008

Wu, D. D., Kefan, X., Hua, L., Shi, Z., \& Olson, D. L. (2010). Modelling technological innovation risks of an entrepreneurial team using system dynamics: An agent-based perspective. Technological Forecasting \& Social Change, 77(6), 857-869. https://doi.org/10.1016/j.techfore.2010.01.015

Yan, R. (2017). Optimization approach for increasing revenue of perishable product supply chain with the Internet of Things. Industrial Management \& Data Systems, 117(4), 729-741.

https://doi.org/10.1108/IMDS-07-2016-0297

\section{APPENDIX}

\section{Notations}

$\mu$ - mean.

SD - standard deviation. 